\title{
Women's awareness and periconceptional use of folic acid: data from a large European survey
}

This article was published in the following Dove Press journal:

International Journal of Women's Health

24 April 2013

Number of times this article has been viewed

Johannes Bitzer'

Ariane von Stenglin ${ }^{2}$

Ralf Bannemerschult ${ }^{3}$

'Department of Obstetrics and Gynecology, University Women's Hospital of Basel, Basel, Switzerland; ${ }^{2}$ Global Market Research, Bayer HealthCare Pharmaceuticals, Berlin, Germany; ${ }^{3}$ Women's Healthcare Medical Affairs and Pharmacovigilance Region Europe, Bayer HealthCare Pharmaceuticals, Berlin, Germany
Correspondence: Johannes Bitzer Department of Obstetrics and Gynecology, University Women's Hospital of Basel, Spitalstrasse 21, 403। Basel, Switzerland

Tel +4I 6I2659099

Fax +4I 612659199

Email jbitzer@uhbs.ch
Objective: To investigate the awareness and use of folic acid in European women of child-bearing age, particularly in the setting of pregnancy and pregnancy planning.

Methods: Between November 2009 and December 2009, women aged 15-49 years old from 18 European countries completed a 30-minute structured questionnaire either online or via face-to-face interviews. To achieve nationally representative samples for each country quotas were set for age, education, income, and regional distribution.

Results: A total of 22,925 women participated in the survey. Of the respondents, $58 \%$ had at least one biological child, and of these $38 \%$ reported that their first pregnancy was not planned. Nearly $60 \%$ of women who planned their pregnancy indicated that they had stopped using their method of contraception without first consulting a doctor or another health care professional. Overall, $70 \%$ reported that they had heard of folic acid and $40 \%$ stated that they knew the benefits of folic acid. However, when prompted to indicate which diseases and/or birth defects folic acid can protect against, only $17 \%$ knew that folic acid can reduce the risk of neural tube defects/spina bifida.

Conclusions: A large proportion of European women of child-bearing age in this survey were unaware that periconceptional folic acid supplementation reduces the risk of birth defects.

Keywords: folic acid supplementation, neural tube defects, pregnancy, women, periconceptional period, survey

\section{Introduction}

"Neural tube defects" (NTDs) is a term used to describe a range of potentially debilitating and sometimes fatal conditions, the most common of which are anencephaly (characterized by total or partial absence of the brain) and spina bifida (characterized by the presence of a bony vertebral defect). ${ }^{1}$ NTDs are the second most common birth defect after congenital cardiac malformations, ${ }^{2}$ the latter including septal defects, patent ductus arteriosus, and narrowing of the valves. ${ }^{3}$ The main cause of NTDs are abnormalities that occur during neurulation, a process that results in the formation of the neural tube and ultimately the spinal cord, brain, and central nervous system. ${ }^{1}$ Neurulation is usually complete by 28 days postconception. ${ }^{1}$

There is well-documented evidence that the occurrence of NTDs can be reduced if women receive folate supplementation in the periconceptional period. ${ }^{4}$ Many countries currently recommend that women planning to become pregnant receive $400 \mu \mathrm{g} /$ day of folic acid at least 1 month prior to conception and for up to 3 months postconception. ${ }^{5-7}$ Despite such recommendations, the decline in the prevalence of NTDs has fallen short of expectations; ${ }^{8,9}$ in the UK and Ireland, for example, NTD prevalence has declined 
by $32 \%$ since the implementation of folic acid supplementation policies, ${ }^{9}$ far short of the $72 \%$ reduction suggested by a Cochrane review of five clinical trials. ${ }^{4}$

There is, therefore, an urgent need to better understand the awareness and behavior of women regarding pregnancy and folic acid consumption. A number of studies have examined the awareness and use of folic acid in individual countries. ${ }^{10-17}$ To our knowledge, there have been no large-scale surveys conducted to date to examine the overall awareness and use of folic acid among women in a wide range of European countries. This report aims to investigate the awareness and use of folic acid in women of child-bearing age, mainly in the setting of pregnancy and pregnancy planning, in Europe.

\section{Methods}

During November 2009 and December 2009, a European survey was conducted online (or face-to-face where necessary) in 18 countries: Austria, Czech Republic, Denmark, France, Germany, Greece (face-to-face), Italy, The Netherlands, Norway, Poland, Portugal (face-to-face), Russia, Spain, Sweden, Switzerland, Turkey (face-to-face), the Ukraine (face-to-face), and the UK. Face-to-face interviews were deemed necessary in countries where the overall female population was incongruent with the online female population, thus restricting the sampling procedure. In Turkey, Greece, the Ukraine, and Portugal, internet utilization overall tends to be restricted primarily to the upper education and income segments. In addition, in Turkey and the Ukraine, online access is restricted primarily to urban regions. Countries were selected with the aim of ensuring the highest possible coverage of the European female population. The 30-minute structured questionnaire was pretested in two countries (Germany and the UK) by performing three or four pilot interviews via a web conference. For the majority of the questions in the survey, the answers were predefined.

Data were collected by GfK Healthcare, Germany, which is an independent global market research vendor. Funding for this survey was provided by Bayer HealthCare Pharmaceuticals. The target was to survey approximately 2000 women in each of France, Germany, the UK, Italy, and Spain, approximately 500 in Greece, and approximately 1000 in the remaining countries. Different sample sizes for each country were chosen for two main reasons: first, to account for different population sizes across countries; and second, due to budget constraints. Larger sample sizes were included in some countries in order to allow more detailed analyses of subgroups on a national level. Women aged 15-49 years were recruited via purposive sampling from an existing GfK con- sumer online panel, setting quotas for age, education, income, and regional distribution in order to achieve nationally representative samples for each country. In order to qualify for the survey women had to complete a screening questionnaire. Women who had been sterilized or received a hysterectomy were automatically excluded from further questioning. The remainder of the questionnaire was designed to determine the women's awareness and use of contraceptive methods in more detail, their behavior and attitude towards contraception, their use of physicians and other information resources when planning pregnancy, and their awareness of folic acid and its benefits. Women received an incentive of $€ 3.60$ for completing the survey. Data analysis was conducted using the software IBM SPSS Statistics (IBM Corporation, Armonk, NY, USA). Countries were analyzed individually; however, when calculating aggregated European results, country data were weighted according to the population size of women aged 15-49 years in each country. This report presents data from the survey relating to the awareness and use of folic acid, and the corresponding section of the questionnaire is included in the Supplementary materials.

\section{Results}

In total, 22,925 women completed the survey. The number of women included and excluded in each country is shown in Table 1. Table 2 presents the unweighted and weighted sociodemographic characteristics of the survey

Table I Proportion of women included and excluded from the sample in each country

\begin{tabular}{llll}
\hline Country & Enrolled, & $\begin{array}{l}\text { Excluded, } \\
\mathbf{n}(\%)\end{array}$ & $\begin{array}{l}\text { Final sample, } \\
\mathbf{n}\end{array}$ \\
\hline Austria & 1099 & $104(9)$ & 995 \\
Czech Republic & 1111 & $48(4)$ & 1063 \\
Denmark & 1215 & $147(12)$ & 1068 \\
France & 2088 & $63(3)$ & 2025 \\
Germany & 2189 & $211(10)$ & 1978 \\
Greece & 506 & $6(1)$ & 500 \\
Italy & 2083 & $68(3)$ & 2015 \\
Netherlands & 1098 & $85(8)$ & 1013 \\
Norway & 1116 & $97(9)$ & 1019 \\
Poland & 1041 & $0(0)$ & 1041 \\
Portugal & 1028 & $24(2)$ & 1004 \\
Russia & 1044 & $27(3)$ & 1017 \\
Spain & 2111 & $123(6)$ & 1988 \\
Sweden & 1060 & $48(5)$ & 1012 \\
Switzerland & 1223 & $130(11)$ & 1093 \\
Turkey & 1035 & $24(2)$ & 1011 \\
Ukraine & 1022 & $6(1)$ & 1016 \\
United Kingdom & 2252 & $185(8)$ & 2067 \\
Total Europe & 24,321 & $1396(6)$ & 22,925 \\
\hline & & &
\end{tabular}


Table 2 Patient sociodemographic characteristics

\begin{tabular}{|c|c|c|}
\hline Characteristic & $\begin{array}{l}\text { Unweighted } \\
\text { sample } \\
(n=22,925)\end{array}$ & $\begin{array}{l}\text { Weighted } \\
\text { sample } \\
(n=22,925)\end{array}$ \\
\hline Age (years), mean (95\% Cl) & $33(33.0-33.2)$ & $33(32.4-32.6)$ \\
\hline \multicolumn{3}{|l|}{ Biological children } \\
\hline Yes, \% & 54 & 58 \\
\hline Number, mean $(95 \% \mathrm{Cl})$ & $\mathrm{I} .8(\mathrm{I} .78-\mathrm{I} .8 \mathrm{I})$ & $\mathrm{I} .7(\mathrm{I} .72-\mathrm{I} .75)$ \\
\hline Height $(\mathrm{m})$, mean $(95 \% \mathrm{Cl})$ & $1.65(1.653-1.657)$ & $1.65(1.650-1.654)$ \\
\hline Weight $(\mathrm{kg})$, mean $(95 \% \mathrm{Cl})$ & $67(66.4-67.0)$ & $66(65.3-65.9)$ \\
\hline \multicolumn{3}{|l|}{ Employment status, \% } \\
\hline Part-time/full-time employed & 63.3 & 61.1 \\
\hline Staying at home/unemployed & 23.4 & 27.3 \\
\hline Student & 13.2 & 11.6 \\
\hline \multicolumn{3}{|l|}{ Marital status, \% } \\
\hline Married/living with partner & 61.3 & 64.2 \\
\hline $\begin{array}{l}\text { Steady relationship, } \\
\text { not living together }\end{array}$ & 15.3 & 15.1 \\
\hline $\begin{array}{l}\text { Single/without a steady } \\
\text { relationship or other }\end{array}$ & 23.5 & 20.6 \\
\hline
\end{tabular}

Abbreviations: $\mathrm{n}$, number; $\mathrm{Cl}$, confidence interval.

respondents. Overall, $58 \%$ of the respondents had at least one biological child.

\section{Obstetric history and contraception}

Of the combined European respondents who had at least one biological child, $38 \%$ reported that their first pregnancy was unplanned (Figure 1). In general, the rates of unplanned pregnancy were fairly similar between the countries, ranging between $25 \%$ and $47 \%$ (with the exception of
The Netherlands, which had the lowest rate of unplanned pregnancy at $16 \%$ ).

Of the women who did plan their first pregnancy, just under one-fifth (18\%) reported that they had consulted their doctor or another health care professional prior to stopping their birth control. More than half (56\%) of the women who planned their first pregnancy reported that they stopped using their method of contraception without first consulting their doctor or another health care professional (Figure 2). The majority of the remaining women either had not used a contraceptive before (19\%), or did not recall their behavior at that time point (4\%). Frequencies varied considerably between the countries. The proportion of women who reported not consulting their doctor or another health care professional before stopping birth control in order to become pregnant was highest in Sweden (85\%) and The Netherlands (81\%). In contrast, only around one-third of women in Turkey (32\%) and Poland (33\%) did not consult their doctor under such circumstances.

\section{Awareness and use of folic acid All women}

Overall, $70 \%$ of the women reported that they had heard of folic acid before, and $40 \%$ stated that they knew the benefits of folic acid. However, when the women were prompted to indicate which diseases and/or birth defects folic acid can protect against, only $17 \%$ of the overall sample knew

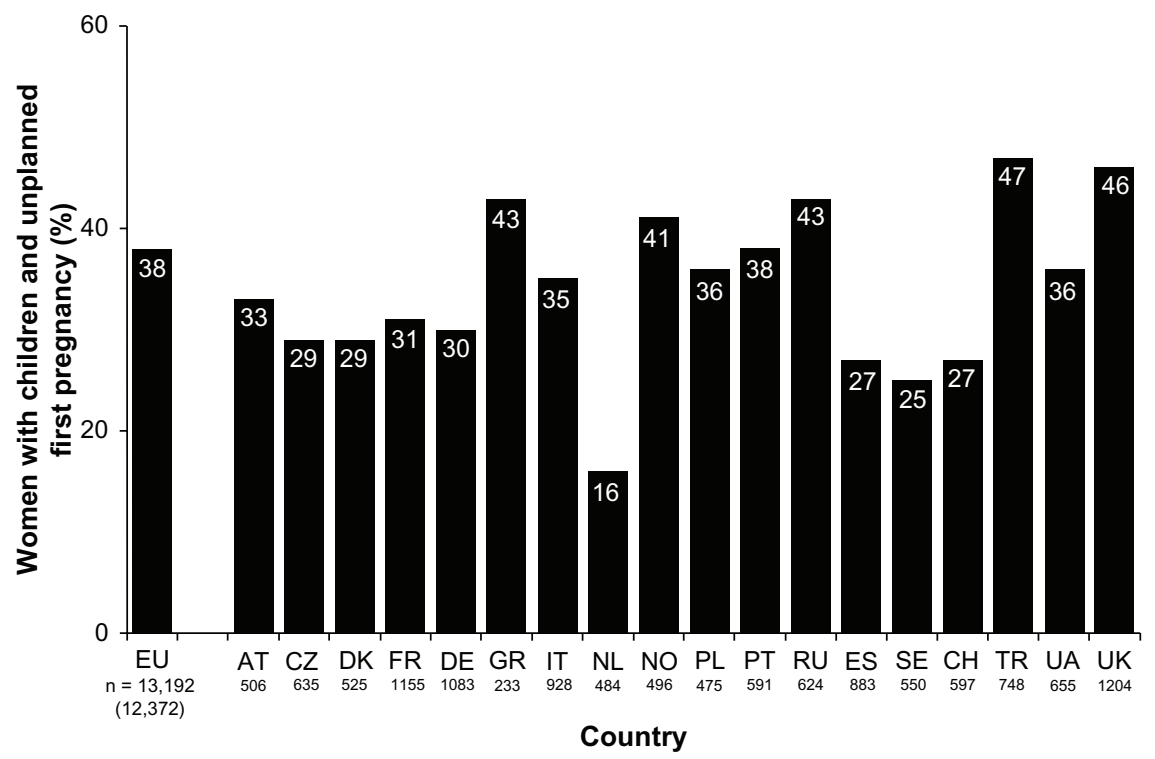

Figure I The proportion of European women with at least one biological child who answered "yes" to the question, "Now please think of the pregnancy with your first child, was this a planned or unplanned pregnancy?".

Notes: European aggregated data are based on weighted samples (unweighted n number shown in brackets). Data for the individual countries are based on unweighted samples. Abbreviations: EU, total Europe; AT, Austria; CZ, Czech Republic; DK, Denmark; FR, France; DE, Germany; GR, Greece; IT, Italy; NL, Netherlands; NO, Norway; PL, Poland; PT, Portugal; RU, Russia; ES, Spain; SE, Sweden; CH, Switzerland; TR, Turkey; UA, Ukraine; UK, United Kingdom; n, number. 


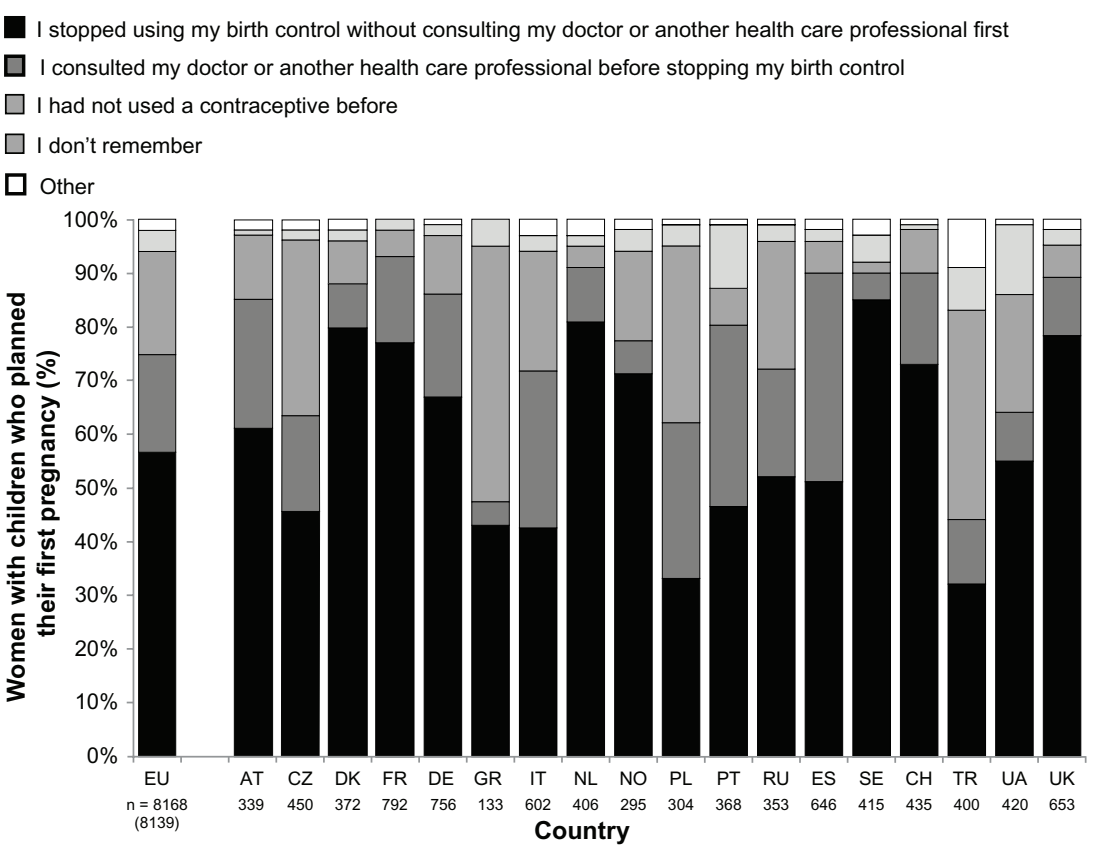

Figure 2 Among European women with biological children and who planned their first pregnancy, responses to the question, "When you were making plans to become pregnant with your first child, which of the following did you do?".

Notes: European aggregated data are based on weighted samples (unweighted n number shown in brackets). Data for the individual countries are based on unweighted samples.

Abbreviations: EU, total Europe; AT, Austria; CZ, Czech Republic; DK, Denmark; FR, France; DE, Germany; GR, Greece; IT, Italy; NL, Netherlands; NO, Norway; PL, Poland; PT, Portugal; RU, Russia; ES, Spain; SE, Sweden; CH, Switzerland; TR, Turkey; UA, Ukraine; UK, United Kingdom; n, number.

that folic acid can reduce the risk of NTDs/spina bifida (Figure 3).

The rate of awareness of folic acid and knowledge about its benefits differed across countries, with the highest rates of awareness in the UK and Poland $(>90 \%)$ and the lowest rates in Turkey and Greece $(<40 \%)$. A similar trend was observed for those who knew that folic acid can protect against NTDs/spina bifida, although the rates were particularly low in Greece, Russia, Turkey, the Ukraine $(<3 \%)$, and France (7\%). Considering the other potential options given in this question (where more than one option could be chosen), the following percentages of the overall sample indicated that folic acid can protect against anemia (16\%), autism (3\%), cystic fibrosis (4\%), Down syndrome $(7 \%)$, thrombosis $(3 \%)$, and cardiovascular disease/health ( $8 \%)$.

Awareness and knowledge of the benefits of folic acid were particularly low among young women. For example, only $42 \%$ of the teenagers in the sample had heard of folic acid before, only $15 \%$ reported that they were aware of its benefits, and only $3 \%$ knew that folic acid could reduce the risk of NTDs/spina bifida (Figure 4). However, women's awareness of folic acid and knowledge of its benefits did increase after they had given birth to a child compared with those who had not had a child (Figure 4).
In total, only $37 \%$ of the respondents had taken folic acid at some point ( $7 \%$ at the time of the survey); the most common reason given was because of advice from a doctor or other health care professional (52\%). This was followed by the woman being pregnant (33\%) or planning to become pregnant (18\%). Only $28 \%$ of those women currently trying to become pregnant (versus $55 \%$ of pregnant women) were taking a folic acid supplement even though guidelines recommend that all these women should take a folate supplement every day (Figure 5). However, adherence to folic acid intake was reported to be low; only $56 \%$ of women using folic acid while trying to become pregnant reported that they took their supplement every day; $38 \%$ reported that, on average, they missed $1-2$ out of 7 days, and $6 \%$ reported missing $\geq 3$ days out of 7 . This adherence level was comparable to women using folic acid, who were already pregnant; only $63 \%$ took their supplement every day, while $30 \%$ missed $1-2$ days and $7 \%$ missed $\geq 3$ out of 7 days.

\section{Women with biological children}

Of the women with a biological child and who were aware of folic acid, $62 \%$ received advice to take folic acid either while they were pregnant or while planning a pregnancy, and of these women, $89 \%$ actually took folic acid (Figure 6). In contrast, of the $38 \%$ of women who did not receive such 
- Aware of folic acid

Know the benefits of folic acid

$\square$ Know folic acid reduces the risk of neural tube defects/spina bifida

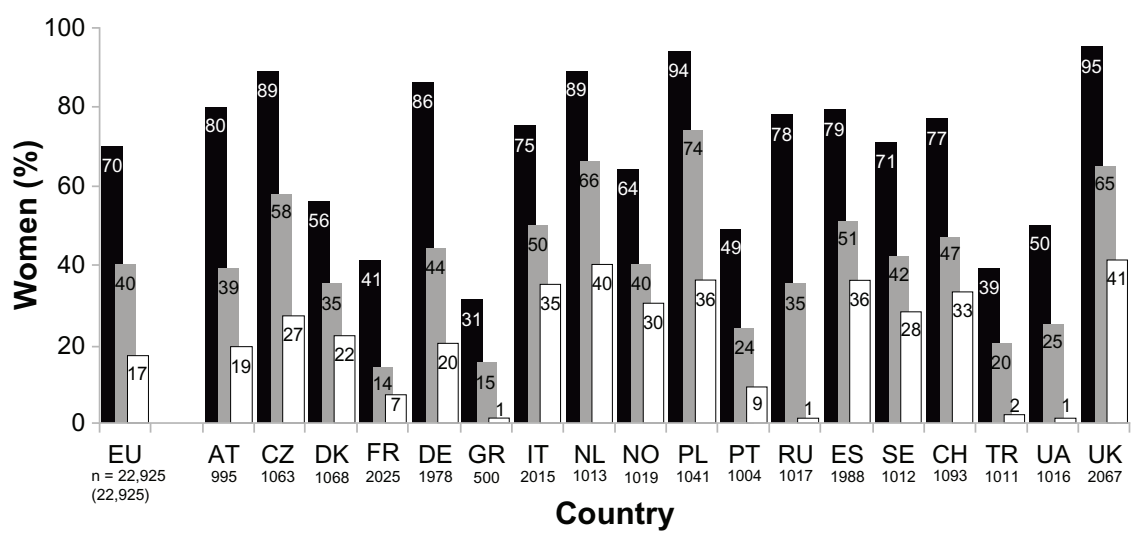

Figure 3 The proportion of European women who answered "yes" to the questions, "Have you heard of folic acid?" and "Do you know what the benefits of folic acid are?" and the proportion of women who identified neural tube defects/spina bifida when asked, "Which of the following diseases/birth defects can folic acid protect against?". Notes: The following answers were possible: anemia, autism, cystic fibrosis, Down syndrome, neural tube defects/spina bifida, thrombosis, cardiovascular disease/ cardiovascular health, and “I don't know." More than one answer could be chosen. Data are shown by country. European aggregated data are based on weighted samples (unweighted $\mathrm{n}$ number shown in brackets). Data for the individual countries are based on unweighted samples.

Abbreviations: EU, total Europe; AT, Austria; CZ, Czech Republic; DK, Denmark; FR, France; DE, Germany; GR, Greece; IT, Italy; NL, Netherlands; NO, Norway; PL, Poland; PT, Portugal; RU, Russia; ES, Spain; SE, Sweden; CH, Switzerland; TR, Turkey; UA, Ukraine; UK, United Kingdom; n, number.

advice only $14 \%$ took periconceptional folic acid of their own accord. The predominant source of information/advice on folic acid was reported to be from a gynecologist (79\%), followed by a general practitioner $(17 \%)$, or a midwife $(16 \%)$. The main reasons reported by the women for not taking folic acid when pregnant or trying to become pregnant were: deficient advice ("No one advised me to take it," 43\%) and lack of awareness ("I didn’t know about folic acid," 40\%).

\section{Discussion}

This survey of more than 20,000 European women of childbearing age showed that a large proportion of the sample is unaware of the need for folic acid supplementation, particularly during the periconceptional period. While $70 \%$ of the respondents indicated that they had heard of folic acid, less than one-half (40\%) indicated that they knew what the benefits of folic acid are and even fewer (less than one-fifth)

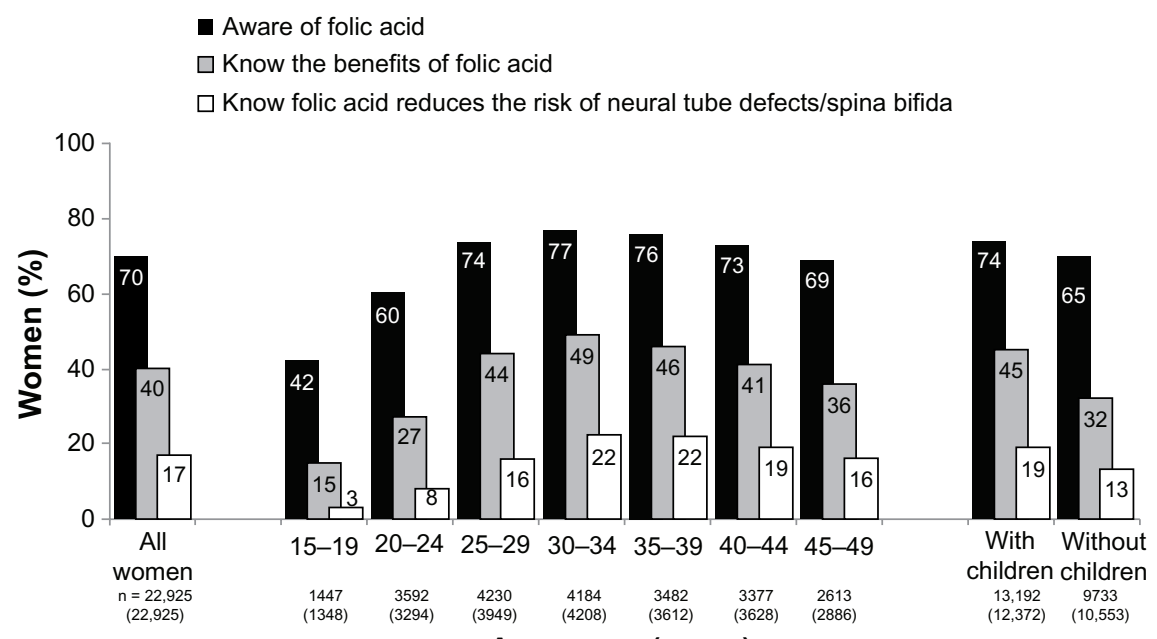

Figure 4 The proportion of European women who answered "yes" to the questions, "Have you ever heard of folic acid?" and "Do you know what the benefits of folic acid are?" and the proportion of women who identified neural tube defects/spina bifida when asked, "Which of the following diseases/birth defects can folic acid protect against?". Notes: The following answers were possible: anemia; autism; cystic fibrosis; Down syndrome; neural tube defects/spina bifida; thrombosis; cardiovascular disease/ cardiovascular health; I don't know. More than one answer could be chosen. Data are shown by age and for women with and without children. European aggregated data are based on weighted samples (unweighted $\mathrm{n}$ number shown in brackets).

Abbreviation: $n$, number. 


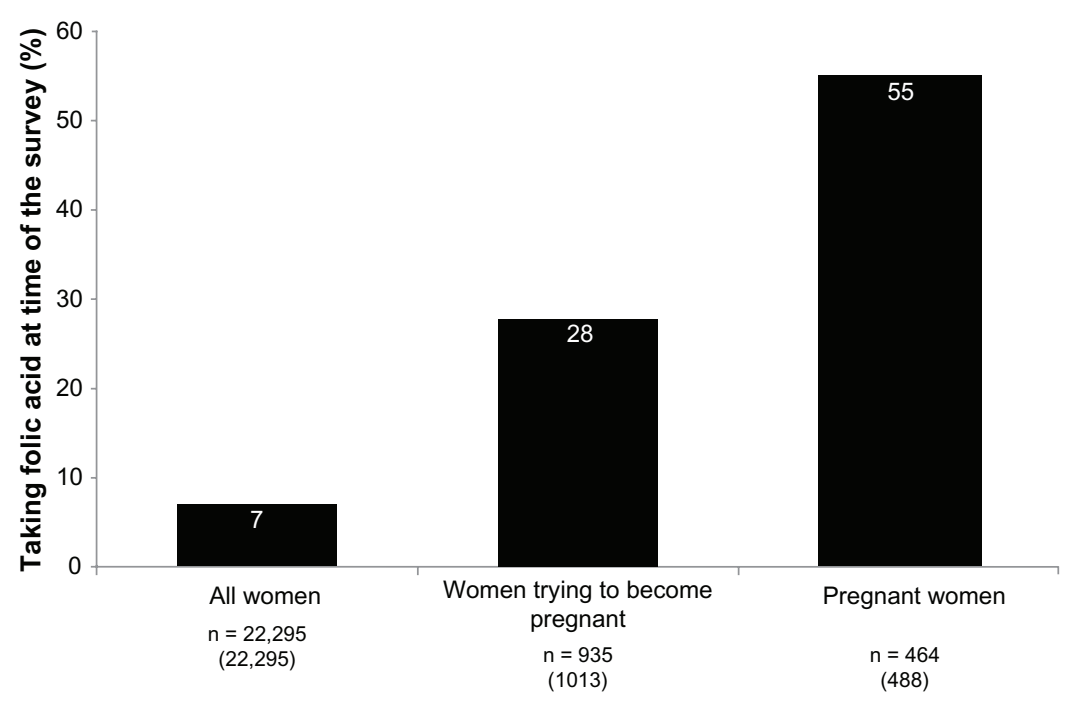

Figure $\mathbf{5}$ The proportion of European women taking folic acid at the time of the survey.

Note: European aggregated data are based on weighted samples (unweighted $\mathrm{n}$ number shown in brackets).

Abbreviation: $\mathrm{n}$, number.

knew, when prompted, that folic acid can protect against NTDs/spina bifida. On average, less than $40 \%$ of the women had ever taken folic acid.

These findings are comparable to those of a number of other studies. In a survey of 4515 women of child-bearing age in Argentina, Brazil, Canada, France, Germany, Italy, Russia, the UK, and the USA, $83 \%$ of women surveyed had heard of folic acid and 55\% knew that folic acid reduces the risk of NTDs. ${ }^{18}$ In a survey of 148 women living in Vancouver, Canada, most of the women (95\%) had heard of folic acid, while only $25 \%$ knew that it could prevent birth defects. ${ }^{15}$ Similarly, a self-administered questionnaire of 578 women

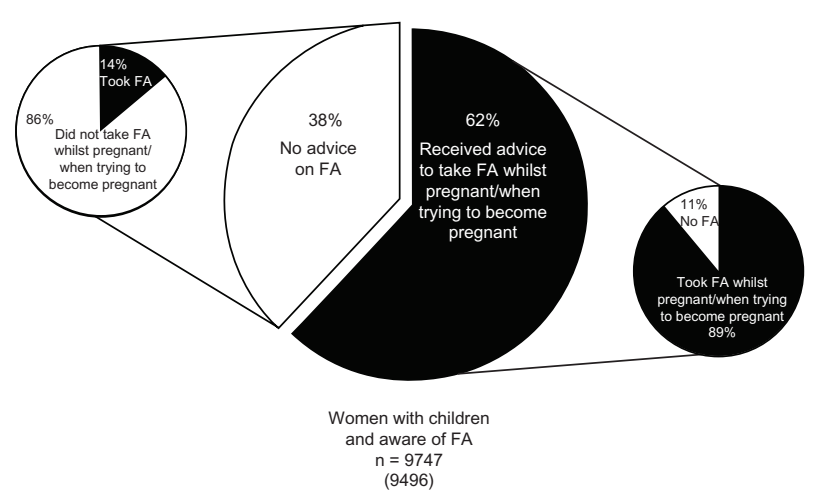

Figure 6 The proportion of European women with biological children and aware of FA who answered "yes" to the question, "Did you receive any advice/information to take folic acid either whilst you were pregnant or when you were thinking of becoming pregnant?" and "Again thinking of the pregnancy with your first child, did you take a folic acid supplement whilst you were pregnant or when you were trying to become pregnant for the first time?"

Note: European aggregated data are based on weighted samples (unweighted $n$ number shown in brackets).

Abbreviations: FA, folic acid; n, number. in Western Australia demonstrated that the majority (89\%) of the women had heard, seen, or read about a link between folate and birth defects. ${ }^{11}$ In the USA, the March of Dimes Foundation Survey of approximately 2000 women aged 18-45 years also found that a large proportion had heard of folic acid, but only a few knew that folic acid could prevent birth defects, and that it needs to be taken before pregnancy. ${ }^{19}$ Similar to the present study, in the March of Dimes Foundation Survey those aged less than 24 years had the lowest rates of awareness, which indicates a particular need to educate younger women on the benefits of the periconceptional use of folic acid..$^{20}$

Health care providers can play an important role in counseling women on the benefits and timely use of folic acid and to motivate them to take folic acid when planning pregnancy or when pregnant. In this survey, the most common source of information on folic acid was reported to be from a gynecologist (79\%), which is similar to other studies. ${ }^{10}$ The importance of such advice can be observed by the fact that, when women received advice on folic acid intake when planning a pregnancy or when pregnant, the majority did go on to take folic acid. In contrast, periconceptional use of folic acid in women who did not receive advice was very low. In some cases the opportunity to provide timely counseling regarding folic acid supplementation prior to pregnancy can be missed because even women who plan their pregnancy may stop their method of contraception without first consulting their doctor or another health care professional about their plans to become pregnant; indeed, this was observed in nearly $60 \%$ of women in the current survey who planned 
their first child. Similar findings have been noted in recent surveys conducted among women of child-bearing potential ${ }^{18}$ and physicians. ${ }^{21}$

There is accumulating evidence that even with the introduction of government policies, clinical recommendations, and health education campaigns, the decrease in the incidence of NTDs/spina bifida has been lower than anticipated. ${ }^{8,9}$ A contributing factor to low folate levels prior to conception is the high number of unplanned pregnancies. In this survey, $38 \%$ of the women reported that their first pregnancy was unplanned, which is consistent with a global survey among women of child-bearing age (36\%), ${ }^{18}$ and with other studies with rates ranging between $10 \%$ and $62 \% .^{22,23}$ In unplanned pregnancies, women are unable to commence periconceptional supplementation, as was noted in a study of Danish women. ${ }^{24}$

An additional issue with taking daily folate supplements is compliance. The level of adherence with folic acid intake was similar between women who were trying to become pregnant and with those who were pregnant; in this survey, $44 \%$ and $37 \%$ of women, respectively, reported that they forgot to take their folic acid supplement at least once a week. Similarly, in a study of Swiss women, only $5 \%$ of the women were found to fully comply with folic acid recommendations, and in many cases the doctors did not know their patients' true folic acid intake. ${ }^{25}$ Elevating and maintaining optimal folate levels is essential because the occurrence of NTDs is known to be directly linked to maternal folate status in the periconceptional period. ${ }^{26}$ Increasing red blood cell folate levels lessens the risk of an NTD-affected pregnancy. A maternal red blood cell folate concentration of $\geq 906 \mathrm{nmol} / \mathrm{L}$ (400 ng/mL) is associated with a very low risk of NTDs ( 0.8 per 1000 births $).{ }^{26}$ Current European guidelines recommend that women receive a folic acid intake of $400 \mu \mathrm{g}$ /day at least 1 month during preconception and up to the first 3 months postconception, ${ }^{5,6}$ but as indicated here and in other studies, folate intake is still inadequate..$^{20,27,28}$

It is therefore imperative that initiatives are implemented across Europe to increase awareness and knowledge of the benefits of folic acid among women of child-bearing age. Preconceptional counseling should be integrated into school curricula on health and sex education and into family planning consultations for contraception; while the latter may seem counterintuitive, family planning consultations represent an excellent opportunity to advise women about future pregnancies and preconceptional health care interventions. Implementing such strategies should be of particular value in younger age groups, in which knowledge and awareness of folic acid is particularly low, as shown in our survey. All women of child-bearing age, including those who are not planning pregnancy in the near future, should receive information and advice on the appropriate use of folic acid in order to make an informed decision. It has been suggested that in countries where food fortification is not permitted, creative, structural public health strategies are required to promote the use of folic acid to lessen the risk of NTDs. ${ }^{29}$ In addition, it would be desirable to find alternative ways to increase folic acid consumption in women of child-bearing age other than through food fortification and folate supplements. Folate-fortified oral contraceptives have been identified as a reasonable delivery vehicle for improving folate status in women of childbearing age. ${ }^{30}$ Two folate-fortified combined oral contraceptives were approved in the USA in 2010 for the improvement of folate status in women who desire contraception; one was comprised of ethinylestradiol (EE) $20 \mu \mathrm{g} / \mathrm{drospirenone} 3 \mathrm{mg} / \mathrm{levomefolate}$ calcium $451 \mu \mathrm{g}$, and the other was compromised of EE $30 \mu \mathrm{g} /$ drospirenone $3 \mathrm{mg}$ / levomefolate calcium $451 \mu \mathrm{g} .{ }^{31} \mathrm{~A}$ double-blind randomized study showed that folate status improved during 26 weeks of treatment with EE $30 \mu \mathrm{g} /$ drospirenone $3 \mathrm{mg} /$ levomefolate calcium $451 \mu \mathrm{g}$, and folate concentrations declined slowly following the cessation of folate intake. ${ }^{32}$

The findings in this report are subject to the inherent limitations of using a survey. First, many of the questions in this survey had predefined answers, and this means that the true answer might not have been provided as an option for some women. In addition, some of the questions required past recall, such as the intake of folic acid. The answers may not, therefore, reflect the actual extent of knowledge and consumption of folic acid of the entire population. Second, apart from the countries that used face-to-face interviews, the online nature of this survey may have been a limitation, as women without internet access or those who were not computer literate would not have been included. This may have meant that our sample was biased towards women of a higher education or income level. Hence, there may be a tendency to exclude and underestimate the number of women of child-bearing age from lower socioeconomic groups or with lower educational status. In addition, women were selected from an existing online panel, which will have limited the results to women who had already signed up to participate in studies, leading to a high response rate. Finally, because the majority of countries used online surveys, there was no means to obtain clarification of any ambiguous or missing answers; moreover, questions may have been subject to individual interpretation or recall bias. Despite these limitations, 
our results provide valuable insight into the awareness and utilization of folic acid in women across Europe.

In conclusion, many women in this European survey were unaware of the importance of taking folic acid during the periconceptional period to reduce the risk of NTDs. The survey therefore highlights a real unmet need to provide women of child-bearing age with appropriate counseling and education regarding the benefits and timely use of folic acid supplementation. With this in mind, each consultation between a woman and her health care professional should be used as a means of education. Family planning consultations represent an excellent opportunity to advise women about future pregnancies and preconceptional health care interventions such as folic acid.

\section{Acknowledgments}

Funding for this study was provided by Bayer HealthCare Pharmaceuticals. The authors would like to thank Clare Wheatcroft and Claire Byrne of inScience Communications, Springer Healthcare, for medical writing assistance; funding for this was provided by Bayer HealthCare Pharmaceuticals.

\section{Disclosure}

Johannes Bitzer has participated in advisory boards for Bayer HealthCare Pharmaceuticals, Merck Sharp and Dohme (MSD), Lilly, Solvay Pharma, and Boehringer Ingelheim, and has lectured at meetings supported by Bayer HealthCare Pharmaceuticals, MSD, Lilly, Solvay Pharma, and Boehringer Ingelheim. Dr von Stenglin and Dr Bannemerschult are employees of Bayer HealthCare Pharmaceuticals.

\section{References}

1. Botto LD, Moore CA, Khoury MJ, Erickson JD. Neural-tube defects. N Engl J Med. 1999;341(20):1509-1519.

2. Cheschier N; for ACOG Committee on Practice Bulletins-Obstetrics. ACOG practice bulletin. Neural tube defects. Number 44, Jul 2003. (Replaces committee opinion number 252, Mar 2001). Int J Gynaecol Obstet. 2003;83(1):123-133.

3. National Heart, Lung, and Blood Institute. Types of congenital heart defects [webpage on the Internet]. Bethesda, MD: United States Department of Health and Human Services; 2011. Available from: http:// www.nhlbi.nih.gov/health/health-topics/topics/chd/types.html. Accessed June 12, 2012.

4. De-Regil LM, Fernández-Gaxiola AC, Dowswell T, Peña-Rosas JP. Effects and safety of periconceptional folate supplementation for preventing birth defects. Cochrane Database Syst Rev. 2010;10:CD007950.

5. European Surveillance of Congenital Anomalies (EUROCAT). Special Report: Prevention of Neural Tube Defects by Periconceptional Folic Acid Supplementation in Europe. Part IIa-Country Specific Chapters (Austria to Ireland). Newtonabbey, Ireland: European Surveillance of Congenital Anomalies; 2009. Available from: http://www.eurocatnetwork.eu/content/Special-Report-NTD-3rdEd-Part-IIA.pdf. Accessed October 6, 2010.
6. European Surveillance of Congenital Anomalies (EUROCAT). Special Report: Prevention of Neural Tube Defects by Periconceptional Folic Acid Supplementation in Europe. Part IIb-Country Specific Chapters (Italy to UK). Newtonabbey, Ireland: European Surveillance of Congenital Anomalies; 2009. Available from: http://www.eurocatnetwork.eu/content/Special-Report-NTD-3rdEd-Part-IIB.pdf. Accessed October 6, 2010.

7. US Preventive Services Task Force. Folic acid for the prevention of neural tube defects: US Preventive Services Task Force recommendation statement. Ann Intern Med. 2009;150(9):626-631.

8. Centers for Disease Control and Prevention (CDC). Spina bifida and anencephaly before and after folic acid mandate - United States, 1995-1996 and 1999-2000. MMWR Morb Mortal Wkly Rep. 2004; 53(17):362-365.

9. Busby A, Abramsky L, Dolk H, Armstrong B; for Eurocat Folic Acid Working Group. Preventing neural tube defects in Europe: population based study. BMJ. 2005;330(7491):574-575.

10. Baykan Z, Oztürk A, Poyrazoğlu S, Gün I. Awareness, knowledge, and use of folic acid among women: a study from Turkey. Arch Gynecol Obstet. 2011;283(6):1259-1253.

11. Oddy WH, Miller M, Payne JM, Serna P, Bower CI. Awareness and consumption of folate-fortified foods by women of childbearing age in Western Australia. Public Health Nutr. 2007;10(10):989-995.

12. Pötzsch S, Hoyer-Schuschke J, Seelig M, Steinbicker V. Knowledge among young people about folic acid and its importance during pregnancy: a survey in the Federal State of Saxony-Anhalt (Germany). J Appl Genet. 2006;47(2):187-190.

13. Sayed AR, Nixon J, Bourne DE. Folic acid awareness among women of reproductive age in Cape Town. S Afr Med J. 2006;96(1):12.

14. Kondo A, Kamihira O, Shimosuka Y, Okai I, Gotoh M, Ozawa H. Awareness of the role of folic acid, dietary folate intake and plasma folate concentration in Japan. J Obstet Gynaecol Res. 2005;31(2):172-177.

15. French MR, Barr SI, Levy-Milne R. Folate intakes and awareness of folate to prevent neural tube defects: a survey of women living in Vancouver, Canada. J Am Diet Assoc. 2003;103(2):181-185.

16. Ringel S, Lahat E, Elizov T, et al. Awareness of folic acid for neural tube defect prevention among Israeli women. Teratology. 1999; 60(1):29-32.

17. Castilla EE, Dutra MG. Folate awareness among South American women. Lancet. 1997;349(9053):735.

18. von Stenglin A, Buchwald S, Lynen R. Women's awareness and use of folate supplements prior to and during pregnancy: a global perspective. Eur J Contracept Reprod Health Care. 2010;15(s1):111-112.

19. Green-Raleigh K, Carter H, Mulinare J, Prue C, Petrini J. Trends in folic acid awareness and behavior in the United States: the Gallup Organization for the March of Dimes Foundation surveys, 1995-2005. Matern Child Health J. 2006;10(Suppl 5):S177-S182.

20. Centers for Disease Control and Prevention (CDC). Use of supplements containing folic acid among women of childbearing age - United States, 2007. MMWR Morb Mortal Wkly Rep. 2008;57(1):5-8.

21. von Stenglin A, Buchwald S, Lynen R. Physicians' knowledge and prescribing practices of folic acid supplementation: a global perspective. Eur J Contracept Reprod Health Care. 2010;15(s1):112-113.

22. Ray JG, Singh G, Burrows RF. Evidence for suboptimal use of periconceptional folic acid supplements globally. BJOG. 2004;111(5): 399-408.

23. Finer LB, Henshaw SK. Disparities in rates of unintended pregnancy in the United States, 1994 and 2001. Perspect Sex Reprod Health. 2006;38(2):90-96.

24. Knudsen VK, Orozova-Bekkevold I, Rasmussen LB, Mikkelsen TB, Michaelsen KF, Olsen SF. Low compliance with recommendations on folic acid use in relation to pregnancy: is there a need for fortification? Public Health Nutr. 2004;7(7):843-850.

25. Poretti A, Anheier T, Zimmermann R, Boltshauser E; for Swiss Pediatric Surveillance Unit (SPSU). Neural tube defects in Switzerland from 2001 to 2007: are periconceptual folic acid recommendations being followed? Swiss Med Wkly. 2008;138(41-42):608-613. 
26. Daly LE, Kirke PN, Molloy A, Weir DG, Scott JM. Folate levels and neural tube defects. Implications for prevention. JAMA. 1995;274(21): 1698-1702.

27. European Surveillance of Congenital Anomalies (EUROCAT). Special Report: Prevention of Neural Tube Defects by Periconceptional Folic Acid Supplementation in Europe. Newtonabbey, Ireland: European Surveillance of Congenital Anomalies; 2009. Available from: http:/ www.eurocat-network.eu/content/Special-Report-NTD-3rdEd-Part-I. pdf. Accessed October 6, 2010.

28. Centers for Disease Control and Prevention (CDC). Trends in wheatflour fortification with folic acid and iron - worldwide, 2004 and 2007. MMWR Morb Mortal Wkly Rep. 2008;57(1):8-10.

29. Eichholzer M, Tönz O, Zimmermann R. Folic acid: a public-health challenge. Lancet. 2006;367(9519):1352-1361.
30. United States Food and Drug Administration. Summary minutes advisory committee for reproductive health drugs meeting December 15 , 2003 [webpage on the Internet]. Bethesda, MD: United States Food and Drug Administration; 2003. Available from: http://www.fda. gov/ohrms/dockets/ac/03/minutes/4002M1_Final.htm. Accessed December 20, 2012.

31. Lassi ZS, Bhutta ZA. Clinical utility of folate-containing oral contraceptives. Int J Womens Health. 2012;4:185-190.

32. Diefenbach K, Trummer D, Ebert F, et al. Ethinylestradiol/drospirenone/ levomefolate calcium versus ethinylestradiol/drospirenone + folic acid: folate status during 24 weeks of treatment and over 20 weeks following treatment cessation. Int J Womens Health. 2013;5:149-163. 


\section{Supplementary material}

Table SI Questionnaire

\begin{tabular}{ll}
\hline GI. Have you ever heard of folic acid? & \\
Yes & $\square$ I Go to G2 \\
No & $\square 2$ Go to HI
\end{tabular}

The next series of questions will ask about if and why you have taken folic acid. In these questions, we are interested in occasions when you deliberately took a supplement of folic acid.

G2. Have you ever taken a folic acid supplement?
Yes
$\square$ I Go to G3a
No
$\square 2$ Go to G5a

G3a. Do you currently take a folic acid supplement?
Yes
$\square$ I Go to G3c
No
$\square 2$ Go to G4

G3b. deleted

G3c. Is the folic acid supplement you are currently taking a prescription product or a nonprescription product (over-the-counter product)? Prescription product

Nonprescription product (over the counter)

Don't know

G3d. Is the folic acid supplement you are currently taking a multivitamin product or a single vitamin supplement? Prenatal multivitamin product Other multivitamin product

$\square 2$

Single vitamin supplement, containing only folic acid $\quad \square 3$

Don't know

G3e. How frequently are you supposed to take your folic acid supplement?

Every day

5-6 times a week

3-4 times a week

$\square 2$

2-3 times a week

$\square 3$

Once a week

$\square 4$

Once a week

$\square 5$

Less frequently than once a week $\quad \square 6$

Don't know $\quad \square 99$

G3f. In an average week, how many times have you forgotten or have you chosen not to take your folic acid tablet?

Never

I day out of 7

$\square$ I

2 days out of 7

3 days out of 7

$\square 3$

4 days out of 7

$\square 4$

5 days out of 7

$\square 5$

6 days out of 7

$\square 6$

7 days out of 7

$\square 8$

G4. What are the reasons why you are currently taking or have been taking a folic acid supplement before?

Please tick all that apply.

A doctor/health care professional advised it $\quad \square$ ।

A friend/relative advised me to take it $\quad \square 2$

Because I am anemic $\quad \square 3$

Because I am planning to become pregnant $\quad \square 4$

Because I am pregnant $\quad \square 5$

Because it has general health benefits $\quad \square 6$

I read about it and heard it was good for me $\quad \square 7$

Because it is in my multivitamins $\quad \square 8$

Because I have a folic acid deficiency $\quad \square 9$

Because I might not be getting enough folic acid in my normal diet $\quad \square 10$

Because I am breast feeding $\quad \square$ II

Because I had premenstrual symptoms $\quad \square$ I2 
Because I had problems with my menstrual bleeding

$\square 13$

Other (please specify):

$\square 14$

No specific reasons

$\square 15$

G5a. Do you know what the benefits of folic acid are?

Yes, I know what the benefits of folic acid are

$\square$ । Go to G5b

No, I don't know what the benefits of folic acid are

$\square 2$ Go to $G 6$

G5b. Which of the following diseases/birth defects can folic acid protect against?

Please tick all that apply.

Anemia

$\square$ I

Autism

$\square 2$

Cystic fibrosis

$\square 3$

Down syndrome

$\square 4$

Neural tube defects/spina bifida

$\square 5$

Thrombosis

$\square 6$

Cardiovascular disease/cardiovascular health

$\square 7$

I don't know

G6. Now please think of the pregnancy with your first child, was this a planned or an unplanned pregnancy?

Planned

$\square$ I Go to G7

Unplanned

$\square 2$ Go to G8

G7. When you were making plans to become pregnant with your first child, which of the following did you do?

I stopped using my birth control without consulting my doctor or another $\quad \square$ ।

health care professional first

I consulted my doctor or another health care professional before

stopping my birth control

I had not used a contraceptive before $\quad \square 3$

Other (please specify): $\square \quad \square 4$

I don't remember $\quad \square 99$

G8. After you personally found out about the pregnancy with your first child (for example by using a pregnancy test), approximately how much time passed by until you went to see your gynecologist or another health care professional?

I week or less

$\square$ I

2 weeks

$\square 2$

3 weeks

$\square 3$

4 weeks

$\square 4$

5 weeks or more

$\square 5$

I don't remember

$\square 99$

G9. Did you know about the benefits of folic acid related to birth defects at any of the following points in time?

Tick all that apply.

At the time I was thinking of becoming pregnant for the first time

$\square$ I

At the time I stopped using contraception and tried to become pregnant

$\square 2$

At the time I was pregnant with my first child

$\square 3$

I didn't know about the benefits of folic acid at any of the abovementioned

$\square 4$ time points

GI0. Did you receive any advice/information to take folic acid either whilst you were pregnant or when you were thinking of becoming pregnant? Yes

$\square$ I Go to GII

No

$\square 2$ Go to GI2

GII. Which sources of information made you aware to take folic acid whilst you were pregnant or when you were thinking of becoming pregnant? Please tick all that apply.

Gynecologist

Primary care physician/general practitioner

Other kind of doctor $\quad \square 3$

Midwife $\quad \square 4$

Nurse $\quad \square 5$

Pharmacist $\quad \square 6$

$\begin{array}{lr}\text { Friends } & \square 7\end{array}$

Partner/husband $\quad \square 8$

Parents $\quad \square 9$

Siblings $\quad \square 10$ 
I already knew I should take folic acid $\quad \square$ । I

I read about it in a magazine/newspaper $\quad \square 12$

I read about it in an information leaflet provided in a waiting room $\quad \square$ I3

I read about it in an information leaflet provided in a pharmacy $\quad \square$ I4

I saw something on the internet $\quad \square 15$

I saw something on TV $\quad \square 16$

I can't remember $\quad \square$ I7

GI2. Again thinking of the pregnancy with your first child, did you take a folic acid supplement whilst you were pregnant or when you were trying to become pregnant for the first time?

Yes

$\square$ I Go to GI3a

No $\quad \square 2$ Go to GI4

GI3a. At which time point did you start to take folic acid?

Before I found out about my pregnancy $\quad \square$ I Go to GI3b

After I found out about my pregnancy $\quad \square 2$ Go to GI3b

I don't remember $\quad \square 99$ Go to GI4

GI3b. How many months [before you found out about your pregnancy]/[after you found out about your pregnancy] did you start to take folic acid ? Number of months:

If, less than a month, please enter days

Number of days:

If, more than a year please enter years

Number of years:

GI4. What is the reason why you didn't take folic acid when you were pregnant for the first time or when you were trying to become pregnant for the first time?

\section{Please tick all that apply.}

I didn't think it was important/necessary/didn't know about $\quad \square$

the benefits of folic acid

I didn't know about folic acid $\quad \square 2$

There was enough folic acid in my diet $\quad \square 3$

No one advised me to take it $\quad \square 4$

I forgot to take it regularly $\quad \square 5$

I thought it might have a negative effect $\quad \square 6$

Vitamins can cause digestive problems $\quad \square 7$

I felt too sick to take it $\quad \square 8$

I don't like to take pills every day $\quad \square 9$

Because of the costs $\quad \square 10$

Other (please specify): $\square \square$ II

There is no particular reason $\quad \square 12$

Folic acid is a vitamin B and important for women across all ages and life stages. It is difficult to gain sufficient levels of folic acid from a normal diet. Particularly women in the fertile age range tend not to have sufficient levels of this vitamin. This vitamin is even more important for women who wish to become pregnant at some stage of their life, because folic acid is needed for the healthy development of an unborn baby. Sufficient levels of folic acid are needed right from the moment of conception, even before the pregnancy is known about.

Suppose there were an oral contraceptive that is additionally supplemented with folic acid and so combines a birth control pill and folic acid in just one small pill. This means the pill would prevent you from getting pregnant and improve the folic acid level in your body. This pill would not lead to any additional side effects or health related problems than the current I-month pill.

GI5. How likely are you to consider using this pill?

Not likely at all

Not very likely

Neutral

Somewhat likely

Very likely 
International Journal of Women's Health

Dovepress

\section{Publish your work in this journal}

The International Journal of Women's Health is an international, peerreviewed open-access journal publishing original research, reports, editorials, reviews and commentaries on all aspects of women's healthcare including gynecology, obstetrics, and breast cancer. The manuscript management system is completely online and includes Visit http://www.dovepress.com/testimonials.php to read real quotes from published authors.

Submit your manuscript here: http://www.dovepress.com/international-journal-of-womens-health-journal 